\title{
Comparison of Ketorolac-Chlorpromazine With Meperidine-Promethazine for Treatment of Exacerbations of Chronic Pain
}

\author{
Lewis E. Mebl-Madrona, MD, PbD
}

Background: The aim was to compare the efficacy and safety of a combination of intramuscular ketorolac and chlorpromazine for the treatment of acute exacerbations of chronic pain with the more commonly used regimen of intramuscular meperidine and promethazine.

Methods: Use-effective case series were drawn from a real-life, rural emergency department practice, in which 200 consecutive patients coming to a rural emergency department with acute exacerbations of chronic pain syndromes were assigned on an every-other basis in a single-blind fashion to one of the two treatment conditions. Patients were given intramuscular doses of either $60 \mathrm{mg}$ of ketorolac plus $50 \mathrm{mg}$ of chlorpromazine ( $75 \mathrm{mg}$ of chlorpromazine for patients weighing more than $100 \mathrm{~kg}$ ), or $50 \mathrm{mg}$ of meperidine plus $25 \mathrm{mg}$ of promethazine (50 mg of promethazine for patients weighing more than $75 \mathrm{~kg}$ ); patients weighing more than $100 \mathrm{~kg}$ were given 1.5 doses. Patients older than 65 years or whose blood pressure at the time of injection was less than $110 / 70 \mathrm{mmHg}$ were given half-doses. Patients could receive one additional half-dose injection if they had no results within 30 to 60 minutes after the first injection. Patients were assessed on self-report and on a verbal and visual analog scale of pain rating. Temperature, blood pressure, heart rate, and respirations were monitored every 15 minutes.

Results: Both regimens performed well, with more than 90 percent of patients reporting good or excellent improvement on acute exacerbations of chronic pain. Ketorolac-chlorpromazine offered significant advantages compared with meperidine-promethazine when patients rated their pain on a visual analog pain scale $(P<0.05)$ but not on a verbal scale. Adverse reactions were minimal and consisted of more respiratory tract depression with meperidine and more vertigo or dizziness with chlorpromazine. There was no difference in incidence of hypotension between the two groups.

Conclusions: The combination of ketorolac and chlorpromazine is a safe and efficacious alternative to meperidine plus promethazine for the treatment of exacerbations of chronic pain in the rural emergency department setting. (J Am Board Fam Pract 1999;12:188-94.)

Exacerbations of chronic pain conditions are frequently encountered in the emergency department, with low-back pain and abdominal pain among the most common complaints. Narcotic analgesics, such as meperidine, have been the mainstay of emergency department therapy for these exacerbations, but these therapies are associated with the potential for abuse and addiction. In

Submitted, revised, 12 December 1998.

From the Center for Complementary Medicine and Departments of Family Practice and Internal Medicine, University of Pittsburgh Medical Center - Shadyside; and Department of Family Practice, University of Pittsburgh School of Medicine, Pittsburgh. Address reprint requests to Lewis E. Mehl-Madrona, MD, PhD, Center for Complementary Medicine, UPMC-Shadyside, 5200 Centre Ave, Suite 403, Pittsburgh, PA 15232. the emergency department setting, unlike in a small group practice, each physician who sees a patient is often unaware of previous visits for treatments and prescriptions, and patients can have repeated visits for narcotic injections and prescriptions. For some patients this behavior is sufficiently reinforced that they return frequently and become labeled as drug-seekers. Because they might have genuine pain, an alternative to narcotic pain relief is desirable.

Ketorolac has been compared with narcotics for postoperative pain relief. It was superior to diflunisal in reducing pain severity during the first 9 hours of treatment, but only equally effective in overall reduction in pain severity and pain relief at the end of days 1, 2 and 3. Patients taking ketoro- 
lac reported fewer adverse events. ${ }^{1}$ Ketorolac had a significantly faster onset of analgesia than placebo, whereas morphine just failed to reach significance compared with placebo; and there was no difference between the time of analgesic onset for ketorolac and morphine. ${ }^{2}$ Among children with postoperative pain, ketorolac provided analgesia comparable to that of meperidine and significantly reduced opioid requirements, but it was not associated with reduction in postoperative vomiting or length of stay. ${ }^{3}$

The utility of ketorolac in treating acute pain when rapid relief is necessary is thought to be limited because it has a prolonged onset of analgesic action (30 to $60 \mathrm{~min}$ ), and a significant number of patients have exhibited little or no response, slightly more than 25 percent in most studies. ${ }^{4}$ Ketorolac with or without meperidine is significantly better than meperidine alone for pain relief and time elapsed before the need for supplemental meperidine. ${ }^{5}$ Onset of analgesia with intravenous ketorolac was significantly faster than that for intramuscular ketorolac or placebo. ${ }^{6}$ The analgesic response and tolerability of oral ketorolac tromethamine and intramuscular morphine sulfate were significantly superior to placebo but not significantly different from each other. Morphine showed a small advantage compared with ketorolac in peak analgesic effect, but the onset of pain relief was comparable, and the incidence of adverse events favored ketorolac. ${ }^{\text {? }}$

There was no difference in pain behavior scores or recovery times among children receiving either ketorolac or morphine and metoclopramide postoperatively. The incidence of nausea and vomiting during the first 24 hours was less in the ketorolac group. ${ }^{8}$ After abdominal hysterectomy or cholecystectomy, patients receiving ketorolac had lower nursing use scores and higher levels of functioning than patients receiving meperidine during the first 3 postoperative days. Times to first bowel movement, walking without assistance, and first oral fluids were significantly shorter with ketorolac than with meperidine. Most adverse events reported by the patients were mild to moderate. ${ }^{9}$

In a pilot trial the use of ketorolac alone was not satisfactory for management of acute migraine pain because full efficacy for pain occurred in only 37 percent of patients (remarkably similar to a 29 percent response rate for narcotics). Patients did not feel satisfied with their pain relief or ready to leave the emergency department. The addition of chlorpromazine seemed to be very effective, however. Because chlorpromazine alone had been used successfully to treat migraine, ${ }^{10-13}$ I designed a project to compare the combination of ketorolac and chlorpromazine with a more common narcotic combination, meperidine-promethazine, for exacerbation of chronic pain in a rural practice.

The mechanism for the effect of chlorpromazine on pain is incompletely understood but is thought to result from the ability of chlorpromazine to alter the perception of pain. ${ }^{14}$ The effect might also result from the potent antiserotonergic activity of chlorpromazine or its ability to induce an $\alpha$-receptor blockade. ${ }^{15}$ Potential adverse effects include postural hypotension, seizures, and dystonic reactions.

Although randomized trials exist separately comparing ketorolac and chlorpromazine with narcotics for pain relief, no study has yet combined the two drugs. This study does so in a reallife practice, which is arguably different and more complex than the usual randomized, controlled trial environment. The objective was to determine whether a ketorolac-chlorpromazine combination could compare favorably with more common narcotic regimens in a rural emergency department setting.

\section{Methods}

A use-effectiveness case series was developed in which patients were alternately treated with one of the two treatment combinations.

\section{Study Group}

Two hundred patients were recruited from consecutive patients seen by the author. Patients were eligible for inclusion if they had a documented history of seeking treatment for the same pain at the emergency department at least twice in each of the preceding 2 years (minimum of 4 visits within 2 years for the same pain). On each of these visits they had received narcotics. They had no allergies to any of the four medications that would be given. Headache patients were not considered in this study but were part of another project. Patients were excluded if they had any evidence of malignancy; signs of nerve root compression, osteoporosis, and compression fractures; an imminently lifethreatening illness; or if they were pregnant.

This subset of pain patients is burdensome for 
primary care and emergency physicians. Patients whose pain is well controlled with standard, nonnarcotic medications do not frequent the emergency department. The selection criteria were aimed at the subset of patients recurrently using the emergency department and narcotics for acute exacerbations of chronic pain.

Patients were told that two equally accepted methods of treating pain were being compared, either one of which the physician thought would be effective for their pain. They were told that they would receive one of the two treatments, and if it did not work, they would receive the other treatment. Patients who agreed to participate were assigned on an alternating basis to one of the two treatment conditions. Alternate assignment was most practical for the busy emergency department setting. Informed consent was requested, and patients signed a written consent-for-treatment form.

Patients with abdominal pain had been previously evaluated extensively for acute conditions potentially responsive to surgery with negative results. Patients with back pain all reported acute exacerbations of chronic conditions. Patients were not accepted into the study if their back pain was sufficiently mild to allow them to continue working uninterruptedly. All patients with back pain who were included in the study suffered work loss.

A method of administration was needed that would be effective but minimize nursing time. The intravenous route has been studied best, but it is time-intensive for nursing staff; therefore, an intramuscular route of administration was chosen.

\section{Outcome Measurement}

The verbal and visual pain analog scales ${ }^{12,16}$ were already used routinely in the emergency department to rate pain and pain relief before and after the administration of pain medication. These pain-rating scales were administered on admission, 30 minutes after treatment, and at discharge by nurses who were not aware that a study was being conducted. The patient rates pain using five separate verbal categories (Table 2), each of which is associated with a face at five equally spaced intervals ranging from frowning with tears to happy and smiling. This scale was to aid non-Englishspeaking patients. The visual pain analog scale is measured in centimeters with $0 \mathrm{~cm}$ being no pain and $100 \mathrm{~cm}$ being unbearable pain. Side effects and relief of nausea were routinely recorded in the nursing notes.

Before beginning the study, the full-time emergency department nurses were compared in their use of pain-rating scales; the results of more than 1 nurse assessing the same patient reached complete agreement 87 percent of the time. This outcome was expected, because the scale depends primarily on the patients, who must rate their pain from 0 to 10 or choose a point on a visual scale that corresponds to their pain. The rating at time of discharge was used for assessing medication effectiveness. Patients who left before 1 hour were reassessed at the time of discharge. The author's prestudy bias was that the patients treated with meperidine-promethazine would have better pain relief.

\section{Treatment Conditions}

Patients were given intramuscular doses of either (1) $60 \mathrm{mg}$ of ketorolac combined with $50 \mathrm{mg}$ of chlorpromazine, or (2) $50 \mathrm{mg}$ of meperidine combined with $25 \mathrm{mg}$ of promethazine if less than 75 $\mathrm{kg}$ or $50 \mathrm{mg}$ of promethazine of more than $75 \mathrm{~kg}$. Patients older than 65 years were given one-half dosages of all drugs. Patients whose blood pressure at the time of injection was less than 110/70 $\mathrm{mmHg}$ were also given half-doses. Patients weighing more than $100 \mathrm{~kg}$ were given a 1.5 dose. Patients could receive one extra injection of 0.5 $\mathrm{mg} / \mathrm{kg}(0.25 \mathrm{mg} / \mathrm{kg}$ if older than 65 years $)$ if they had no results within 30 to 60 minutes after the first injection. Blood pressures were monitored automatically every 15 minutes for up to 1 hour after injections. Patients with marked hypotension were given a fluid bolus of normal saline solution. If patients were pain-free or sufficiently pain-free to request discharge and had shown no hypotensive tendencies, they could be discharged after 1 half hour of observation (two postinjection blood pressure recordings). Additional medication was not given if any hypotension was observed. Dosages chosen were standard for the respective medications.

Nurses knew which medications they were giving and were asked to use only generic names with patients. The nurses were asked to communicate enthusiasm about whatever medications they used for pain relief, though a bias appeared to exist in favor of meperidine-promethazine being more effective than ketorolac-chlorpromazine. 
Table 1. Demographic Characteristics of Pain Patients.

\begin{tabular}{lccc}
\hline Characteristics & Ket-CPZ & Mep-PMZ & Chi-Square \\
\hline Male, \% & 40 & 39 & 0.0209 \\
Female, \% & 60 & 61 & 0.0209 \\
Age, years & 33.17 & 41.91 & 1.0601 \\
$\quad$ (range) & $(18-91)$ & $(21-81)$ & $(t$-test) \\
$\begin{array}{l}\text { Duration of acute } \\
\text { pain, hours }\end{array}$ & 21.5 & 19.8 & 0.3587 \\
$\quad$ (range) & $(2-431)$ & $(7-350)$ & $(t$-test) \\
Type of pain, \%* & & & \\
Back & 45 & 34 & 2.5316 \\
Abdominal & 36 & 41 & 0.5279 \\
$\quad$ all other & 19 & 25 & 1.0490 \\
Race, \% & & & \\
Hispanic & 35 & 44 & 1.6947 \\
White & 38 & 37 & 0.0213 \\
African American & 20 & 15 & 0.8658 \\
Native American & 7 & 3 & 1.6842 \\
Asian & 0 & 1 & 1.0050 \\
\hline
\end{tabular}

Ket-CPZ - ketorolac-chlorpromazine, Mep-PMZ - meperidinepromethazine.

"The same patient could have more than one type of pain.

\section{Statistical Analysis}

Log-likelihood estimates were used with the chisquare method for calculating levels of statistical significance for comparisons between groups, except that the Student's $t$ test procedure was used for comparing values that were means.

\section{Results}

There were no statistically significant demographic differences between the two groups of patients being treated with ketorolac-chlorpromazine and with meperidine-promethazine (Table 1). Female patients were more common in both groups. $\mathrm{Pa}$ tients were generally in their fourth decade of life. Duration of acute pain was almost 24 hours from exacerbation to arrival at the emergency department. The two most common types of chronic pain were back pain and abdominal pain.

Ketorolac-chlorpromazine and meperidinepromethazine provided similar levels of pain relief as rated by the verbal analog scale (Table 2). Ketorolac-chlorpromazine was better for the relief of nausea. On the visual analog scale, ketorolacchlorpromazine performed better for mean pain rating on discharge and maximum pain rating on discharge (Table 3).

Respiratory tract depression, dry mouth, and vomiting were more common with meperidinepromethazine (Table 4). There were no differences
Table 2. Patients' Pain Assessment Using a Verbal Analog Scale.

\begin{tabular}{lccc}
\hline Pain Assessment & Ket-CPZ & Mep-PMZ & Chi-Square \\
\hline Description of Pain & $(\mathrm{n}=100)$ & $(\mathrm{n}=100)$ & \\
Worse & 4 & 3 & 0.1480 \\
No better & 10 & 10 & 0.0000 \\
Minimal improvement ${ }^{\star}$ & 4 & 15 & 7.0369 \\
Good improvement & 60 & 52 & 3.0202 \\
Excellent improvement & 22 & 20 & 0.5436 \\
Total number improved & 86 & 87 & 0.2861 \\
Effects of nausea & $(\mathrm{n}=49)$ & $(\mathrm{n}=50)$ & \\
Worse & 8 & 7 & 0.1042 \\
No better & 2 & 2 & 0.0000 \\
Minimal improvement ${ }^{\dagger}$ & 1 & 21 & 25.2666 \\
Good improvement & 8 & 10 & 0.2245 \\
Excellent improvement ${ }^{\dagger}$ & 30 & 10 & 21.1564 \\
Total number improved & 39 & 41 & 0.2026 \\
\hline
\end{tabular}

Ket-CPZ - ketorolac-chlorpromazine, Mep-PMZ - meperidinepromethazine.

${ }^{*} P<0.05$.

$+P<0.01$.

otherwise in the incidence of drowsiness, hypotension, nausea, burning at the injection site, or nasal congestion. All patients with marked hypotension responded to a fluid bolus of normal saline.

\section{Discussion}

While not a strict, randomized, clinical trial, this case series shows that the ketorolac-chlorpromazine combination can be successfully used in a rural practice setting and is as effective as narcotics in treating pain. Ketorolac-chlorpromazine had slightly significantly better results on the visual analog scale. This difference between the verbal and visual analog scale might have resulted from the use of faces, but probably has no clinical importance. Ketorolac-chlorpromazine worked better for nausea, presumably because meperidine is known to cause nausea in some patients and because chlorpromazine is a more potent antiemetic than promethazine.

Intravenous chlorpromazine for pain relief of migraine headache has been shown to be superior to intravenous dihydroergotamine or intravenous lidocaine. ${ }^{10}$ More patients experienced persistent headache relief and complete relief. Success rates in the complete relief of pain and nausea have been reported as high as 96 percent in uncontrolled trials. ${ }^{11}$ Placebo-controlled trials have shown significant efficacy of chlorpromazine compared with 
Table 3. Patients' Pain Assessment Using a Visual Analog Scale.

\begin{tabular}{lrrr}
\hline Pain Rating & Ket-CPZ & Mep-PMZ & Chi-Square \\
\hline Initial & & & \\
$\quad$ Minimum & 4.87 & 4.71 & 0.5025 \\
$\quad$ Maximum & 10.00 & 10.00 & 0.0000 \\
$\quad$ Mean & 6.45 & 6.12 & 0.4050 \\
Final & & & \\
$\quad$ Minimum & 0.00 & 0.00 & 0.0000 \\
Maximum* & 5.54 & 8.31 & 2.5511 \\
Mean* & 0.61 & 2.18 & 2.6056 \\
\hline
\end{tabular}

Ket-CPZ - ketorolac-chlorpromazine, Mep-PMZ - meperidinepromethazine.

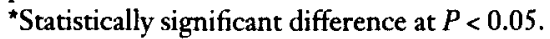

placebo for the side effects of drowsiness and asymptomatic drop in blood pressure $(10 \mathrm{mmHg}$ systolic). ${ }^{12}$ Intravenous chlorpromazine has been compared favorably with intravenous meperidine, ${ }^{14}$ as has intramuscular chlorpromazine. ${ }^{17}$ Others have also reported efficacy of intravenous chlorpromazine. ${ }^{18,19}$ For acute, nonmigrainous headache pain, ketorolac, meperidine, and placebo did not differ in degree of pain relief. ${ }^{20}$

Ketorolac has also been studied elsewhere as an agent for acute pain relief. Among children ketorolac provided a degree of postoperative analgesia comparable with that of meperidine. ${ }^{21}$ In one study ketorolac had a significantly faster onset of analgesia when compared with placebo and no difference in onset of analgesia when compared with morphine, ${ }^{22}$ whereas in another study meperidine had a more rapid onset of action than ketorolac during the first 2 postoperative hours; thereafter, meperidine and ketorolac were equally effective. ${ }^{23}$

Among postoperative adults being medicated for postoperative pain, intramuscular ketorolac and intramuscular morphine had comparable times of analgesic onset and similar analgesic effects. ${ }^{24,25}$ The exception to these findings was a study showing that morphine was more efficacious for the treatment of postoperative pain following tubal ligation. ${ }^{21}$ Similarly, neither intravenous ketorolac nor intravenous morphine adequately controlled moderate to severe postoperative pain among women undergoing major abdominal gynecologic surgery. ${ }^{26}$ Pelvic pain might be different from that of other surgeries. Ketorolac and the combination of ketorolac with morphine performed better than meperidine alone for
Table 4. Number of Adverse Effects Reported by Patients Taking Ketorolac-Chlorpromazine and Meperidine-Promethazine.

\begin{tabular}{|c|c|c|c|}
\hline Adverse Effects & Ket-CPZ & $\begin{array}{c}\text { Mep-PMZ } \\
-\end{array}$ & $\begin{array}{l}\text { Chi } \\
\text { Square }\end{array}$ \\
\hline Drowsiness & 73 & 94 & 21.2303 \\
\hline Nausea & 14 & 17 & 0.3436 \\
\hline Vomiting $^{\dagger}$ & 1 & 6 & 3.7010 \\
\hline Dizziness, vertigo & 6 & 3 & 1.0471 \\
\hline Hypotension & 14 & 10 & 0.7576 \\
\hline Burning at injection site & 2 & 5 & 1.3323 \\
\hline Dry mouth ${ }^{\dagger}$ & 1 & 6 & 3.7010 \\
\hline Nasal congestion & 16 & 18 & 0.1417 \\
\hline Respiratory depression ${ }^{\dagger}$ & 1 & 8 & 5.7010 \\
\hline $\begin{array}{l}\text { Adverse effects other } \\
\text { than sedation }\end{array}$ & 16 & 12 & 0.6645 \\
\hline $\begin{array}{l}\text { Patients receiving fluid } \\
\text { bolus for hypotension }\end{array}$ & 7 & 10 & 0.5786 \\
\hline
\end{tabular}

Ket-CPZ - ketorolac-chlorpromazine, Mep-PMZ - meperidinepromethazine.

${ }^{*} P<0.01$.

${ }^{\dagger} P<0.05$.

renal colic. ${ }^{27}$ Ketorolac was less efficacious than meperidine as an adjunct for conscious sedation before upper gastrointestinal endoscopy. ${ }^{28}$

In patients undergoing cholecystectomy, ketorolac was associated with lower per-case costs in inpatient care (length of stay), direct nursing labor, as-required procedures, and medications relating to emesis and to gastrointestinal distress. Higher per-case costs were recorded for the primary analgesic (study drug) and for supplemental pain medications. In contrast to the substantial difference in the acquisition cost of ketorolac compared with the cost of morphine sulfate or meperidine, the cholecystectomy group taking ketorolac was associated with lower overall resource costs per patient. In joint-replacement procedures, however, the ketorolac group was associated with higher overall resource costs per patient, attributable primarily to a slightly longer postoperative length of stay. ${ }^{29}$

Side effects of chlorpromazine given in the above manner are usually acceptable. Mariani ${ }^{30}$ called attention to 2 patients who received a total of $60 \mathrm{mg}$ of intravenous chlorpromazine (more than is usually used in the above studies); 1 experienced restlessness and an inability to take deep breaths, and the second complained of a dry mouth, restlessness, and a vague dysesthetic feeling. The symptoms in the first patient resolved 
with a 5-mg intravenous dose of diazepam, and the patient was discharged. Symptoms in the second patient spontaneously resolved within 1 hour. Lane and Ross ${ }^{14}$ reported 1 patient who, after chlorpromazine was given intravenously, complained of agitation and vertigo, which also spontaneously resolved.

These paradoxical reactions are known to occur with phenothiazines, including promethazine; they can range from sensorimotor restlessness and agitation to outright toxic psychosis and should be remembered when these medications are used. ${ }^{31,32}$ Considered by some to be part of the spectrum of akathisia, these symptoms can occur after a single parenteral dose. ${ }^{33}$ Women appear to be about twice as likely as men to develop these symptoms. ${ }^{34}$ Patients in renal failure are particularly at risk, perhaps as a result of decreased clearance of phenothiazine metabolites. ${ }^{35}$ These reactions are usually short-lived except in patients in renal failure or who are already taking oral neuroleptics. ${ }^{30}$ The anticholinergic effects of phenothiazines have been implicated as a potential mechanism. ${ }^{31}$

The side effects encountered in this study were relatively minimal. Drowsiness was most common, which was considered desirable, because patients would go home and sleep, and when they awoke, their pain would be considerably reduced from their chronic pain condition. Because most patients visit the emergency department in the evenings, drowsiness is compatible with the patients' desires as well.

The findings of this study are consistent with those described above. For chronic pain the number of patients experiencing good or excellent improvement was high for both therapies.

Chlorpromazine has also been shown to be effective for nonmigrainous headaches, ${ }^{36}$ including subarachnoid hemorrhage and subdural hematoma. This finding and the effectiveness of chlorpromazine in chronic pain syndromes argue for a general effect on pain rather than a specific effect on migraines.

The medical literature on the use of chlorpromazine for acute exacerbations of chronic pain conditions is minimal. No studies could be found of chlorpromazine being combined with ketorolac. This study reports a case series of its use, finding the combination equal to the more standard meperidine-promethazine combination. The added benefits of the ketorolac-chlorpromazine combination are its relative lack of potential for abuse or addiction. Physicians can administer this combination without fear of reinforcing emergency visits to obtain narcotics. The combination of ketorolac and chlorpromazine might be a treatment of choice for acute exacerbations of chronic pain in the emergency setting. A possible role for oral chlorpromazine-nonsteroidal anti-inflammatory drug combinations in the management of chronic pain awaits further study.

Questions unanswered by this report include the effect of the emergency department environment and the act of giving injections for pain, the difference in effectiveness between the same medications given orally and intramuscularly, actual return rates for patients treated each way, and the question of what is lost by giving a narcotic medication. These questions await further studies.

\section{References}

1. Fernandez-Sabate A, Portabella F. Comparative multiple-dose study of ketorolac tromethamine and diflunisal for pain following orthopaedic surgery. $\mathrm{J}$ Int Med Res 1991;19:210-8.

2. Rice AS, Lloyd J, Miller CG, Bullingham RE, O'Sullivan GM. A double-blind study of the speed of onset of analgesia following intramuscular administration of ketorolac tromethamine in comparison to intramuscular morphine and placebo. Anaesthesia 1991;46: 541-4.

3. Bean-Lijewski JD, Hunt RD. Effect of ketorolac on bleeding time and postoperative pain in children: a double-blind, placebo-controlled comparison with meperidine. J Clin Anesth 1996;8:25-30.

4. Catapano MS. The analgesic efficacy of ketorolac for acute pain. J Emerg Med 1996;14:67-75.

5. Cordell WH, Wright $\mathrm{SW}$, Wolfson $\mathrm{AB}$, Timerding BL, Maneatis TJ, Lewis RH, et al. Comparison of intravenous ketorolac, meperidine, and both (balanced analgesia) for renal colic. Ann Emerg Med 1996;28:151-8.

6. Rice AS, Whitehead EM, O'Sullivan G, Lloyd J, Bullingham RE. Speed of onset of analgesic effect of intravenous ketorolac compared to morphine and placebo. Eur J Anaesthesiol 1995;12:313-7.

7. Maslanka MA, de Andrade JR, Maneatis T, Bynum $\mathrm{L}$, DiGiorgio E. Comparison of oral ketorolac, intramuscular morphine, and placebo for treatment of pain after orthopedic surgery. South Med J 1994;87:506-13.

8. Munro HM, Riegger LQ, Reynolds PI, Wilton NC, Lewis IH. Comparison of the analgesic and emetic properties of ketorolac and morphine for paediatric outpatient strabismus surgery. Br J Anaesth 1994; 72:624-8.

9. Gin T, Kan AF, Lam KK, O'Meara ME. Analgesia 
after caesarean section with intramuscular ketorolac or pethidine. Anaesth Intensive Care 1993;21:420-3.

10. Bell R, Montoya D, Shuaib A, Lee MA. A comparative trial of three agents in the treatment of acute migraine headache. Ann Emerg Med 1990;19:1079-82.

11. Iserson KV. Parenteral chlorpromazine treatment of migraine. Ann Emerg Med 1983;12:756-8.

12. McEwen JI, O'Connor HM, Dinsdale HB. Treatment of migraine with intramuscular chlorpromazine. Ann Emerg Med 1987;16:758-63.

13. Lane PL, McLellan BA, Baggoley CJ. Comparative efficacy of chlorpromazine and meperidine with dimenhydrinate in migraine headache. Ann Emerg Med 1989;18:360-5.

14. Lane PH, Ross R. Intravenous chlorpromazinepreliminary results in acute migraine. Headache 1985;25:302-4.

15. Goodman LS, Gilman AG, editors. Goodman and Gilman's the pharmacological basis of therapeutics. 7th ed. New York: Macmillan, 1985:391-408.

16. Scott J, Huskisson EC. Graphic representation of pain. Pain 1976;2:175-84.

17. Davis CP, Torre PR, Williams C, Gray C, Barrett K, Krucke G, et al. Ketorolac versus meperidine-pluspromethazine treatment of migraine headache: evaluations by patients. Am J Emerg Med 1995;13:146-50.

18. Couch JR Jr, Diamond S. Status migrainosus: causative and therapeutic aspects. Headache 1983;23:94101.

19. Kain BF. Nonnarcotic relief of acute migraine. Can Fam Physician 1982;28:2037-8.

20. Shrestha M, Singh R, Moreden J, Hayes JE. Ketorolac vs chlorpromazine in the treatment of acute migraine without aura. A prospective, randomized, double-blind trial. Arch Intern Med 1996;156:1725-8.

21. Green CR, Pandit SK, Levy L, Kothary SP, Tait AR, Schork MA. Intraoperative ketorolac has an opioidsparing effect in women after diagnostic laparoscopy but not after laparoscopic tubal ligation. Anesth Analg 1996; 82:732-7.

22. Burns JW, Aitken HA, Bullingham RE, McArdle CS, Kenny GN. Double-blind comparison of the morphine sparing effect of continuous and intermittent intramuscular administration of ketorolac. $\mathrm{Br} \mathrm{J}$ Anaesth 1991;67:235-8.

23. Folsland B, Skulberg A, Halvorsen P, Helgesen KG. Placebo-controlled comparison of single intramuscular doses of ketorolac tromethamine and pethidine for post-operative analgesia. J Int Med Res 1990;
18:305-14.

24. Cade L, Kakulas P. Ketorolac or pethidine for analgesia after elective laparoscopic sterilization. Anaesth Intensive Care 1995;23:158-61.

25. McGuire DA, Sanders K, Hendricks SD. Comparison of ketorolac and opioid analgesics in postoperative ACL reconstruction outpatient pain control. Arthroscopy 1993;9:653-61.

26. Peirce RJ, Fragen RJ, Pemberton DM. Intravenous ketorolac tromethamine versus morphine sulfate in the treatment of immediate postoperative pain. Pharmacotherapy 1990;10(6 Pt 2):111S-115S.

27. Harden RN, Gracely RH, Carter T, Warner G. The placebo effect in acute headache management: ketorolac, meperidine, and saline in the emergency department. Headache 1996;36:352-6.

28. Dies DF, Clarkston WK, Schratz CL. Intravenous ketorolac tromethamine versus meperidine for adjunctive sedation in upper gastrointestinal endoscopy: a pilot study. Gastrointest Endosc 1996; 43:6-9.

29. Trotter JP, Reinhart SP, Katz RM, Glazier HS. Economic assessment of ketorolac versus narcotic analgesics in postoperative pain management. Clin Ther 1993;15:938-48.

30. Mariani PJ. Adverse reactions to chlorpromazine in the treatment of migraine. Ann Emerg Med 1988; 17:380-1.

31. Diamond JM, Santos AB. Unusual complications of antipsychotic drugs. Am Fam Physician 1982;26: 153-7.

32. Simpson GM, Varga E, Haher J. Psychotic exacerbations produced by neuroleptics. Dis Nerv Syst 1976;37:367-9.

33. Crane GE, Naranjo ER. Motor disorders induced by neuroleptics: a proposed new classification. Arch Gen Psychiatry 1971;24:179-84.

34. Sovner R, DiMascio A. Extrapyramidal syndromes and other neurological side effects of psychotropic drugs. In: Lipton MA, DiMascio A, Killam K. editors. Psychopharmacology: a generation of progress. New York: Raven Press, 1978:1021-32.

35. McAllister CJ, Scowden EB, Stone WJ. Toxic psychosis induced by phenothiazine administration in patients with chronic renal failure. Clin Nephrol 1978;10:191-5.

36. Barclay CL, Shuaib A, Montoya D, Seland TP, Thomas HG. Response of non-migrainous headache to chlorpromazine. Headache 1990;30:85-7. 